\title{
Kajian Pola Aliran di Hilir Pintu Sorong dengan Material Dasar Saluran Pasir Lempung
}

\author{
N.B. Rustiati ${ }^{\mathrm{a} *}$ dan N. Suciani ${ }^{\mathrm{b}}$ \\ aJurusan Teknik Sipil, Fakultas Teknik Universitas Tadulako, Palu, Indonesia, 94112 \\ ${ }^{b}$ Alumni Jurusan Teknik Sipil, Fakultas Teknik Universitas Tadulako, Palu, Indonesia, 94112 \\ *Corresponding author's e-mail: neen211273@gmail.com
}

Received: 15 January 2022; revised: 18 February 2022; accepted: 28 February 2022

\begin{abstract}
The operation of a damaged (jammed) sluice result unsuitable velocity distribution with the design. This causes turbulence of the flow which results the hydraulic jump. The hydraulic jumps as a function of energy absorbers. The large energy will cause damage to the water structure. Therefore, there is a need for research to obtain flow profiles. The aims of the research is to investigate the flow characteristic and hydraulics jump that occurred at downstream of manually moving of sluice gate. The height of opening gate set up variated at $0.4 \mathrm{~cm}$ to $1.4 \mathrm{~cm}$. The range of using variated discharge from $0.108 \mathrm{lt} / \mathrm{s}$ to $0.524 \mathrm{lt} / \mathrm{s}$. The result of investigation showed that the higher of opening gate at the same discharge value the hydraulics characteristic at the downstream of sluice gate decreasing. The hydraulics characteristic are the water depth, hydraulics jump and the flow characteristic. As a results variation discharge and opening gate are subcritical flow.
\end{abstract}

Keywords: sluice gate, hydraulic jump, flow pattern, sandy clay material

\begin{abstract}
Abstrak: Pengoperasian pintu air yang rusak (macet) mengakibatkan adanya distribusi kecepatan tidak sesuai dengan perencanaan. Hal ini menyebabkan terjadi turbulensi aliran yang menghasilkan loncatan air. Loncatan hidrolik berfungsi sebagai peredam energi. Energi yang besar akan mengakibatkan kerusakan pada struktur bangunan air. Karena itu, perlu adanya penelitian untuk mendapatkan profil aliran. Penelitian ini bertujuan untuk mengamati dan mengkaji karakteristik aliran dan loncatan hidrolik yang terjadi pada bagian hilir dari pintu air yang digerakkan secara manual. Pada penelitian ini, tinggi bukaan pintu air bervariasi antara $0,4 \mathrm{~cm}$ sampai $1,4 \mathrm{~cm}$ sedangkan debit aliran bervariasi antara $0.108 \mathrm{lt} / \mathrm{s}$ sampai $0.524 \mathrm{lt} / \mathrm{s}$. Hasil penelitian dan investigasi menunjukkan bahwa semakin tinggi bukaan pintu pada besaran debit yang sama maka karakteristik hidrolik yang terjadi akan menurun. Karakteristik hidrolik tersebut adalah kedalaman aliran, loncatan hidrolik dan sifat aliran. Sebagai hasil dari variasi debit dan tinggi bukaan pintu adalah aliran subkritik.
\end{abstract}

Kata kunci: pintu air, loncatan hidrolik, pola aliran, material pasir lempung

\section{Pendahuluan}

Penetapan Pemilihan pintu air sebagai pengatur debit akibat adanya distribusi kecepatan yang tidak sesuai dengan perencanaan yang dapat menyebabkan turbulensi, dan apabila turbulensi tersebut dibiarkan dalam waktu yang lama dapat menyebabkan material yang berada di bawah pintu air akan tergerus [1]. Pada umumnya tipe aliran melalui saluran terbuka adalah turbulen, karena kecepatan aliran dan kekasaran dinding relatif besar. Aliran melalui saluran terbuka disebut seragam (uniform) apabila berbagai variabel aliran seperti kedalaman, tampang basah, kecepatan dan debit pada setiap tampang di sepanjang aliran adalah konstan. Pada aliran seragam, garis energi, garis muka air dan dasar saluran adalah sejajar sehingga kemiringan dari ketiga garis tersebut adalah sama [2].

Saluran terbuka adalah saluran dimana air mengalir dengan muka air bebas. Pada semua titik di sepanjang saluran, tekanan dipermukaan air adalah sama. Gerakan air pada saluran terbuka berdasarkan efek dari gravitasi bumi dan distribusi tekanan didalam air umunya bersifat hidrostatis. Distribusi tekanan bersifat hidrostatis karena kuantitasnya tergantung dari berat jenis aliran dan kedalaman. Karena berat jenis aliran dapat diasumsikan tetap, maka tekanan hanya tergantung dari kedalamannya; semakin dalam maka tekanannya semakin besar. Namun pada beberapa kondisi bisa ditemukan distribusi tekanan tidak hidrostatis [3]. Dalam saluran terbuka sering terjadi perubahan keadaan aliran, dari aliran sub kritis menjadi super kritis atau sebaliknya. Perubahan semacam ini dinyatakan dalam suatu perubahan berturut dari kedalaman aliran, baik dari permukaan yang tinggi ke rendah atau dari permukaan rendah ke tinggi [4].

Karakter aliran yang paling sesuai untuk mengendapkan partikel sedimen adalah aliran laminar dengan kecepatan yang rendah [5]. Banyak cara dilakukan untuk mendapatkan pola aliran yang seperti ini, atau yang lebih dikenal dengan "plug-flow", seperti merancang posisi inlet dan outlet, mencegah pembentukan gelombang dipermukaan dengan meminimalkan angin, menggunakan baffle/sekat dan merancang bentuk atau geometri dari konstruksi [6].

Loncatan hidrolik berfungsi sebagai peredam sebagian besar energi yang terjadi [7]. Untuk mengidentifikasi permasalahan yang ada diperlukan penelitian yang digunakan untuk mengkaji serta mengamati pola aliran yang terjadi sebagai rekomendasi perlindungan bangunan air dan dapat digunakan untuk menganalisis serta mencoba 
mengatasi masalah pada bangunan-bangunan keairan akibat adanya loncatan hidrolik [8-9].

Keadaan aliran di bawah pintu tergantung dari kedalaman aliran di hilir pintu. Kedalaman aliran di hilir pintu itu sendiri dipengaruhi oleh kemiringan dan kekasaran dasar saluran di hilir pintu [9-10]. Pada kondisi aliran bebas, aliran tidak dipengaruhi oleh loncatan sehingga disebut aliran bebas. Sedangkan loncatan yang dihasilkan disebut loncatan bebas (free jump) [11-13]. Kondisi aliran pada hulu pintu subkritis sedangkan di hilir pintu adalah superkritis [14-15].

\section{Metode Penelitian}

\subsection{Lokasi Penelitian}

Penelitian ini memakai fasilitas yang tersedia pada Laboratorium Hidrolika Jurusan Teknik Sipil Fakultas

Teknik Universitas Tadulako. (Gambar 1), y Model bangunan saluran terbuka yang terbuat dari bahan aklirik dengan lebar saluran (B) $76 \mathrm{~mm}$, tingi saluran (Hsal) 250 $\mathrm{mm}$ dan panjang saluran (L) $5000 \mathrm{~mm}$. Pintu air yang digunakan adalah pintu sorong (sluice gate). Di ujung hulu dipasang balok kayu dan diberi pengaku, balok berfungsi sebagai lantai dasar (rigid bed) di bawah pintu. Di ujung hilir saluran dipasang pintu penangkap sedimen untuk menghalangi sedimen terbawah aliran keluar saluran. Butiran material sedimen disebar dan dipadatkan sepanjang saluran di ujung bawah pintu. Gradasi butiran yang dipakai yaitu butiran tidak seragam. Sampel tanah yang digunakan diambill dari 4 titik yang berbeda. Pompa air untuk suplai aliran air bersih ke model saluran. Bak penampungan air bersih untuk menyuplai air bersih dan dilengkapi alat ukur debit. Meteran taraf (point gauge). Water pass, penggaris, stopwatch, dan kamera.

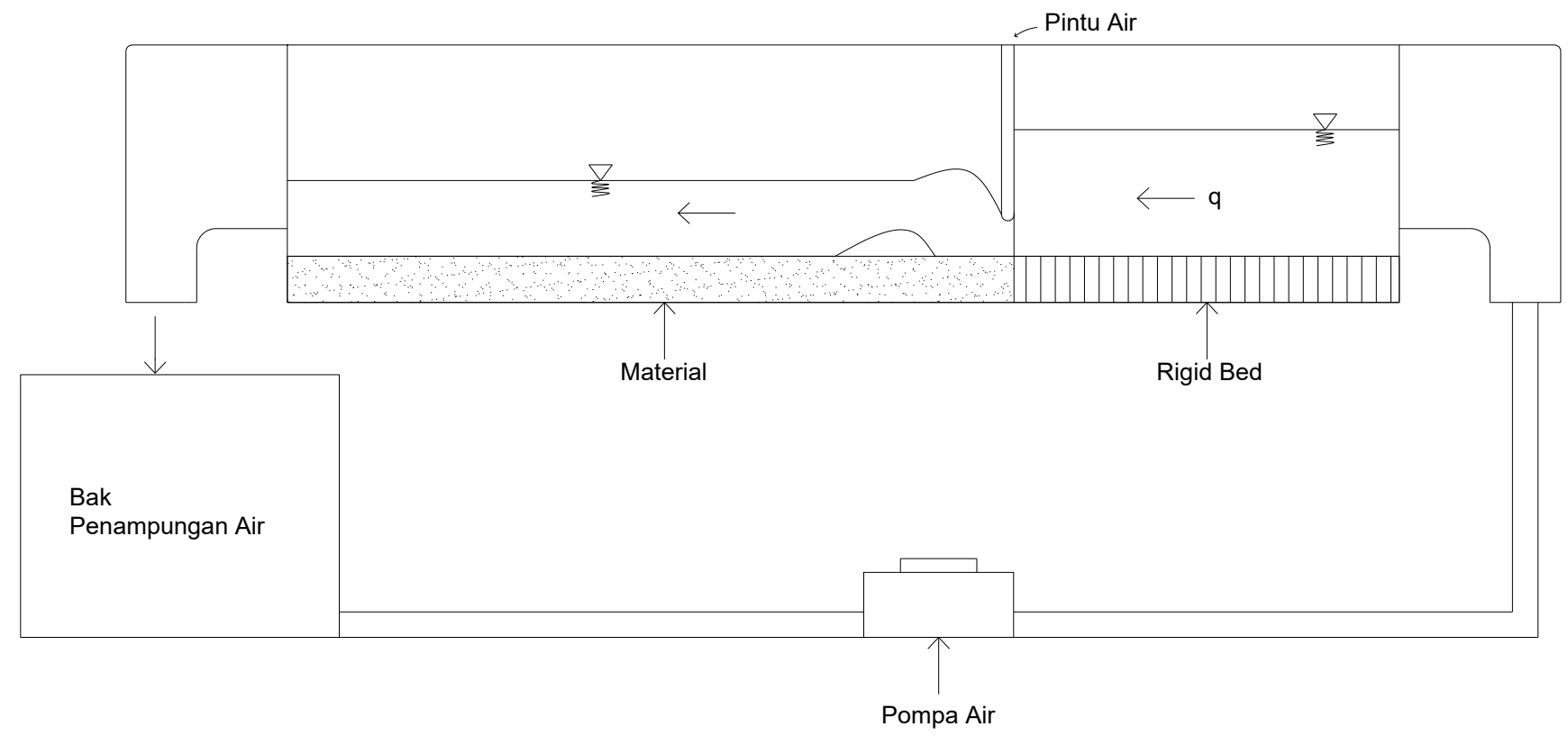

Gambar 1. Peta lokasi penelitian

\subsection{Data}

Data yang digunakan dalam penelitian ini adalah data primer karena merupakan penelitian laboratorium. Adapun data yang diambil adalah data kedalaman aliran di bagian hulu $\left(\mathrm{y}_{0}\right)$, kedalaman aliran tepat dibawah pintu air $\left(\mathrm{y}_{1}\right)$, kedalaman aliran pada awal terjadinya loncatan hidrolik $\left(\mathrm{y}_{2}\right)$, kedalaman aliran pada akhir loncatan hidrolik $\left(\mathrm{y}_{3}\right)$ dan kedalaman aliran di hilir pintu air $\left(\mathrm{y}_{\mathrm{tw}}\right)$ serta Jarak pintu air terhapat awal loncatan hidrolik $\left(\mathrm{x}_{\mathrm{j}}\right)$ dan panjang loncatan hidrolik $(\mathrm{Lj})$.

\subsection{Metode dan Tahapan Penelitian}

Dalam penelitian ini digunakan 9 variasi debit dengan posisi bukaan pintu mulai $0,4 \mathrm{~cm}$ sampai $1,4 \mathrm{~cm}$. Percobaan dimulai dari debit 0,108 liter/detik sampai 0,524 liter/detik. Nilai debit diambil berdasarkan nilai yang diperoleh dari kalibrasi debit di Laboratorium dan bukaan pintu diambil dari $0.4 \mathrm{~cm}-1.4 \mathrm{~cm}$ karena alat pintu sorong di Laboratorium bukaan minimumnya $0.4 \mathrm{~cm}$ dan bukaan maksimumnya $1.4 \mathrm{~cm}$. Untuk bukaan $0.8 \mathrm{~cm}$ dan $1.2 \mathrm{~cm}$ diambil karena saat penyetelan debit untuk setiap kenaikan muka air $0.1 \mathrm{~cm}$ di $\mathrm{y}_{0}$ sangat sulit dikerjakan, maka dari itu di ambil kenaikan muka air 0.4 cm karena lebih mudah debitnya untuk disetel.

Sampel tanah yang digunakan adalah sampel dari daerah pertanian yang berlokasi di Desa Pewunu, Kecamatan Dolo Barat, Kabupaten Sigi, Provinsi Sulawesi Tengah. Material yang digunakan ada 4 sampel dan telah melalui uji analisa saringan dan berat jenis untuk mengetahui jenis material yang digunakan. Tes dilakukan di Laboratorium Geoteknik, Jurusan Teknik Sipil Fakultas Teknik Universitas Tadulako. Material dihamparkan pada saluran hingga ketebalan $5 \mathrm{~cm}$.

Material dihamparkan di hilir pintu sorong sepanjang hilir saluran dengan tebal $5 \mathrm{~cm}$. Setelah itu, material dipadatkan dan diratakan. Bukaan pintu diatur sesuai rencana. Menyalakan pompa dan diesel, sehingga air mengalir dari tandon yang selanjutnya mengalir ke saluran. Mengatur debit yang direncanakan, bersamaan dengan itu, aliran direkam. Mengamati pola aliran sebelum masuk pintu dan sesudah masuk pintu, serta loncatan hidrolik yang terjadi. Setelah keadaan muka air stabil, ukur 
kedalaman aliran di bagian hulu ( $\left.\mathrm{y}_{0}\right)$, kedalaman aliran tepat dibawah pintu air $\left(\mathrm{y}_{1}\right)$, kedalaman aliran pada awal terjadinya loncatan hidrolik $\left(\mathrm{y}_{2}\right)$, kedalaman aliran pada akhir loncatan hidrolik $\left(\mathrm{y}_{3}\right)$ dan kedalaman aliran di hilir pintu air $\left(\mathrm{y}_{\mathrm{tw}}\right)$ serta Jarak pintu air terhapat awal loncatan hidrolik $\left(\mathrm{x}_{\mathrm{j}}\right)$ dan panjang loncatan hidrolik $(\mathrm{Lj})$. Setelah 10 menit atau setelah aliran stabil maka aliran dihentikan.

\subsection{Loncatan Hidrolis}

Loncatan hidrolik terjadi jika aliran superkritis berubah menjadi aliran subkritis pada jarak dan kedalaman tertentu. Aliran superkritis akan mengalami loncatan sampai pada kedalaman aliran yang merupakan dua pertemuan jenis aliran tersebut, yang dinamakan kedalaman konjugasi. Umumnya loncatan hidrolik disertai dengan kenaikan permukaan air secara mendadak dan kehilangan tinggi energi yang cukup besar [9].

Intensitas transpor sedimen $(\mathrm{T})$ adalah banyaknya sedimen yang melawati pada satuan penampang melintang sungai yang dinyatakan dalam berat $(\mathrm{kg} / \mathrm{dt})$ atau volume $\left(\mathrm{m}^{3} / \mathrm{dt}\right)$. Biasanya $\mathrm{T}$ dinyatakan banyaknya sedimen tiap satuan lebar sungai/saluran [5].

\section{Hasil dan Pembahasan}

\subsection{Kalibrasi Debit}

Kalibrasi adalah pengaturan model agar supaya datadata yang ada di model sesuai dengan prototipe, sehingga dapat digunakan sebagai acuan pengukuran selanjutnya. Dalam kalibrasi ini ada beberapa parameter yang diuji yaitu: debit untuk mejaga bahwa pada setiap kali running debitnya selalu konstan, kedalaman muka air hilir untuk memastikan kondisi aliran yang terjadi apakah aliran bebas atau aliran tenggelam. Apabila terjadi perbedaan antara hasil pengukuran di model dengan perhitungan analitis, maka kesalahan tidak boleh melebihi kesalahan maksimum yang diizinkan. Kalibrasi juga untuk memastikan kondisi aliran yang terjadi dimodel dan prototipe adalah sama. Hasil kalibrasi debit disajikan pada Tabel 1.

Tabel 1. Data kalibrasi debit

\begin{tabular}{cccc}
\hline yo (cm) & $\begin{array}{c}\text { Berat } \\
\text { Tampungan } \\
\text { Air (Liter) }\end{array}$ & t (detik) & $\begin{array}{c}\text { L/t=Q } \\
\text { (Liter/detik) }\end{array}$ \\
\hline 6 & 1 & 9.24 & 0.108 \\
\hline 6.6 & 1 & 5.52 & 0.181 \\
\hline 6.8 & 1 & 4.27 & 0.234 \\
\hline 6.9 & 1 & 3.62 & 0.276 \\
\hline 7 & 1 & 2.87 & 0.348 \\
\hline 7.3 & 1 & 2.85 & 0.351 \\
\hline 7.5 & 1 & 2.37 & 0.422 \\
\hline 7.8 & 1 & 1.97 & 0.508 \\
\hline 7.9 & 1 & 1.91 & 0.524 \\
\hline
\end{tabular}

Keterangan : $\mathrm{h}$ = Tinggi muka air di hulu pintu $(\mathrm{cm})$

$\mathrm{L}=$ Berat tampungan air (Liter)

$\mathrm{t}=$ Waktu (detik)

$\mathrm{Q}=\operatorname{Debit}($ Liter/detik)
Berdasarkan Tabel 1 kemudian dibuat hubungan antara kedalaman aliran dan debit aliran, untuk mengetahui kurva debit secara grafis (Gambar 2).

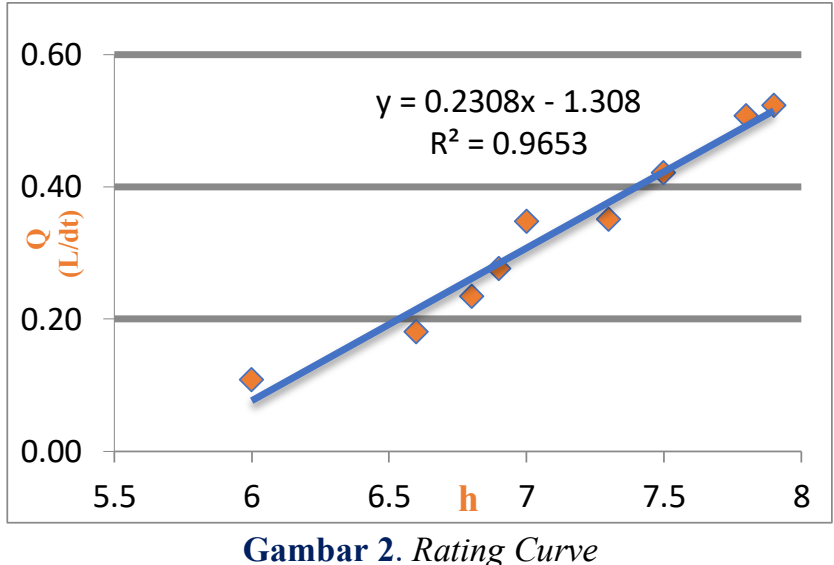

Adapun rancangan percobaan yang dilakukan dalam penelitian ini adalah seperti pada Tabel 2.

Tabel 2. Rancangan bukaan pintu

\begin{tabular}{|c|c|c|}
\hline No & $\begin{array}{c}\text { Debit } \\
\text { (liter/detik) }\end{array}$ & $\begin{array}{l}\text { Bukaan Pintu } \\
(\mathrm{cm})\end{array}$ \\
\hline \multirow{4}{*}{1} & \multirow{4}{*}{0,108} & 0,4 \\
\hline & & 0,8 \\
\hline & & 1,2 \\
\hline & & 1,4 \\
\hline \multirow{4}{*}{2} & \multirow{4}{*}{0,181} & 0,4 \\
\hline & & 0,8 \\
\hline & & 1,2 \\
\hline & & 1,4 \\
\hline \multirow{4}{*}{3} & \multirow{4}{*}{0,234} & 0,4 \\
\hline & & 0,8 \\
\hline & & 1,2 \\
\hline & & 1,4 \\
\hline \multirow{4}{*}{4} & \multirow{4}{*}{0,276} & 0,4 \\
\hline & & 0,8 \\
\hline & & 1,2 \\
\hline & & 1,4 \\
\hline \multirow{4}{*}{5} & \multirow{4}{*}{0,348} & 0,4 \\
\hline & & 0,8 \\
\hline & & 1,2 \\
\hline & & 1,4 \\
\hline \multirow{4}{*}{6} & \multirow{4}{*}{0.351} & 0,4 \\
\hline & & 0,8 \\
\hline & & 1,2 \\
\hline & & 1,4 \\
\hline \multirow{4}{*}{7} & \multirow{4}{*}{0.422} & 0,4 \\
\hline & & 0,8 \\
\hline & & 1,2 \\
\hline & & 1,4 \\
\hline \multirow{4}{*}{8} & \multirow{4}{*}{0.508} & 0,4 \\
\hline & & 0,8 \\
\hline & & 1,2 \\
\hline & & 1,4 \\
\hline \multirow{4}{*}{9} & \multirow{4}{*}{0.524} & 0,4 \\
\hline & & 0,8 \\
\hline & & 1,2 \\
\hline & & 1,4 \\
\hline
\end{tabular}




\subsection{Tunjauan Hidrolis Saluran}

1). Debit dan Kecepatan

Berdasarkan hasil pengamatan kemudian dilakukan analisis pehitungan luas penampang (A) dan kecepatan aliran (v) seperti pada Tabel 3.

$$
\begin{aligned}
\mathrm{A} & =\mathrm{b} \times \mathrm{h} \\
& =0.076 \times 0.25 \\
& =0.019 \mathrm{~m}^{2}
\end{aligned}
$$

Berikut merupakan contoh perhitungan kecepatan pada debit $=0.000108 \mathrm{~m}^{3} / \mathrm{dtk}$ sehingga didapatkan :

$$
\begin{aligned}
\mathrm{Q} & =\mathrm{v} . \mathrm{A} \\
\mathrm{v} & =\frac{\mathrm{Q}}{\mathrm{A}} \\
& =\frac{0.000108}{0.019} \\
& =0.00568 \mathrm{~m} / \mathrm{dtk}=0.5684 \mathrm{~cm} / \mathrm{dtk}
\end{aligned}
$$

Tabel 3. Tabel hasil rekapitulasi kecepatan

\begin{tabular}{cccc}
\hline $\begin{array}{c}\mathbf{Q} \\
\left(\mathbf{m}^{\mathbf{3}} / \mathbf{d e t}\right)\end{array}$ & $\begin{array}{c}\text { Luas } \\
\text { Penampang, } \\
\left.\mathbf{A ~} \mathbf{( m}^{\mathbf{2}}\right)\end{array}$ & $\begin{array}{c}\text { Kec. } \\
(\mathbf{m} / \mathbf{d e t})\end{array}$ & $\begin{array}{c}\text { Kec. } \\
(\mathbf{c m} / \mathbf{d e t})\end{array}$ \\
\hline 0.000108 & 0.019 & 0.00568 & 0.5684 \\
\hline 0.000181 & 0.019 & 0.00953 & 0.9526 \\
\hline 0.000234 & 0.019 & 0.01232 & 1.2316 \\
\hline 0.000276 & 0.019 & 0.01453 & 1.4526 \\
\hline 0.000348 & 0.019 & 0.01832 & 1.8316 \\
\hline 0.000351 & 0.019 & 0.01847 & 1.8474 \\
\hline 0.000422 & 0.019 & 0.02221 & 2.2211 \\
\hline 0.000508 & 0.019 & 0.02674 & 2.6737 \\
\hline 0.000524 & 0.019 & 0.02758 & 2.7579 \\
\hline
\end{tabular}

2). Bilangan Froude

Angka Froude Q $=0.108$ liter $/$ detik $=108 \mathrm{~cm}^{3} /$ detik. Berikut ini adalah contoh perhitungan angka Froude:

$$
\begin{aligned}
\mathrm{v} & =23.7336 \mathrm{~cm} / \text { detik } \\
\mathrm{y} & =0.6 \mathrm{~cm} \\
\mathrm{Fr} & =\frac{\mathrm{v}}{\sqrt{\mathrm{gy}}} \\
& =\frac{23.734}{\sqrt{981 \times 0.6}} \\
& =0.9783 \ldots . . . . \mathrm{Fr}<1 \text { (subkritis) }
\end{aligned}
$$

Perhitungan selanjutnya dihitung secara tabulasi seperti pada Tabel 4. Hasil perhitungan angka Froude $\mathrm{Q}=108$ $\mathrm{cm}^{3} /$ detik dengan $\mathrm{a}=0.4 \mathrm{~cm}$

Tabel 4. Bilangan Froude dan rezim aliran

\begin{tabular}{ccccc}
\hline $\begin{array}{c}\text { Sec- } \\
\text { tion }\end{array}$ & $\begin{array}{c}\text { Tinggi } \\
\text { Muka } \\
\text { Air }(\mathrm{cm})\end{array}$ & $\begin{array}{c}\text { Kecepatan } \\
(\mathrm{cm} / \text { detik })\end{array}$ & $\begin{array}{c}\text { Angka } \\
\text { Froude }\end{array}$ & $\begin{array}{c}\text { Jenis } \\
\text { Aliran }\end{array}$ \\
\hline $\mathrm{Y}_{0}$ & 0.6 & 23.7336 & 0.9783 & Subkritis \\
\hline $\mathrm{Y}_{1}$ & 0.5 & 28.4803 & 1.2860 & Superkritis \\
\hline $\mathrm{Y}_{2}$ & 0.75 & 18.9869 & 0.7000 & Subkritis \\
\hline $\mathrm{Y}_{3}$ & 1.05 & 13.5620 & 0.4226 & Subkritis \\
\hline $\mathrm{Y}_{\mathrm{tw}}$ & 0.7 & 20.3431 & 0.7763 & Subkritis \\
\hline
\end{tabular}

Tabel 5 menyajikan hasil pengamatan variabel terikat pada semua $Q$ dan a yang ditabelkan dan selanjutnya dibuat gambaran secara grafis yang ditunjukan seperti pada Gambar 3.

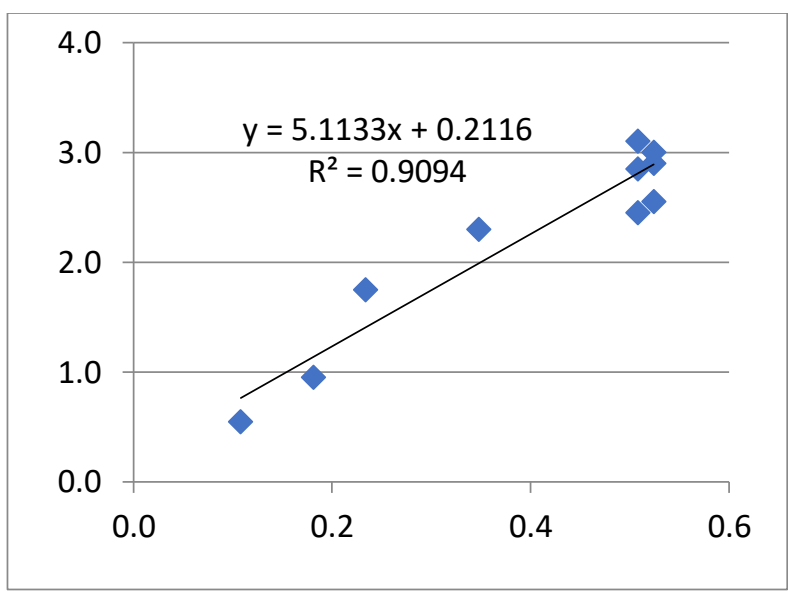

Gambar 3. Grafik hubungan antara debit dan loncatan hidrolik

Gambar 3 menunjukan bahwa semakin besar nilai debit (Q) yang dialirkan semakin panjang pula loncatan air $\left(\mathrm{L}_{\mathrm{j}}\right)$ yang terjadi. Hal ini ditunjukan dengan besaran nilai koefisien determinan $\mathrm{R}^{2}=0.9094$ yang menunjukan bahwa debit (Q) mempunyai pengaruh terhadap perubahan loncatan air.

\section{3). Loncatan Hidrolis}

Karakteristik loncatan air yang diamati ialah kedalaman awal loncatan hidrolik $\left(\mathrm{Y}_{2}\right)$, kedalaman di hilir setelah loncatan hidrolik $\left(\mathrm{Y}_{3}\right)$, dan panjang loncatan hidrolik (Lj) seperti pada Gambar 4. Dari data yang ada dapat dihitung energi spesifik aliran di awal maupun di akhir loncatan hidrolik sehingga dapat diketahui efisiensi yang terjadi pada loncatan hidrolik (Tabel 6).

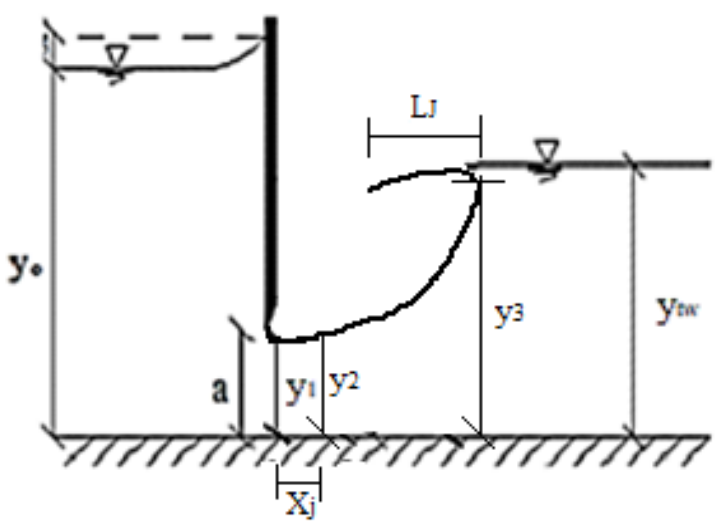

Gambar 4. Sketsa loncatan hidrolik

a) Panjang loncatan $(\mathrm{Lj})$

$\mathrm{Lj} \quad=0.55 \mathrm{~cm}$

b) Energi spesifik

$$
\begin{aligned}
& E=y+\frac{V^{2}}{2 g} \\
& E_{1}=y_{2}+\frac{V 2^{2}}{2 g} \quad=0.75+\frac{360.501^{2}}{2.981}=0.934 \mathrm{~cm}
\end{aligned}
$$


REKOnSTRUKSI TADULAKO: Civil Engineering Journal on Research and Development, Vol. 3(1), March 2022

Tabel 5. Hasil pengamatan variabel bebas dan variabel terikat pada semua $Q$ dan a

\begin{tabular}{ccccccccccc}
\hline & \multicolumn{7}{c}{ Variabel Bebas } & \multicolumn{7}{c}{ Variabel Terikat } \\
\cline { 2 - 12 } No & $\mathrm{Q}$ & $\mathrm{a}$ & $\mathrm{Y}_{0}$ & $\mathrm{Y}_{1}$ & $\mathrm{x}_{\mathrm{j}}$ & $\mathrm{Y}_{2}$ & $\mathrm{~L}_{\mathrm{j}}$ & $\mathrm{Y}_{3}$ & $\mathrm{Y}_{\mathrm{tw}}$ & $\Delta \mathrm{y}$ \\
\cline { 2 - 13 } & $(\mathrm{lt} / \mathrm{det})$ & $(\mathrm{cm})$ & $(\mathrm{cm})$ & $(\mathrm{cm})$ & $(\mathrm{cm})$ & $(\mathrm{cm})$ & $(\mathrm{cm})$ & $(\mathrm{cm})$ & $(\mathrm{cm})$ & $(\mathrm{cm})$ \\
\hline 1 & 0.108 & 0.40 & 0.60 & 0.50 & 0.70 & 0.75 & 0.55 & 1.05 & 0.60 & 0.00 \\
\hline 2 & 0.181 & 0.40 & 0.80 & 0.90 & 1.90 & 1.00 & 0.95 & 1.35 & 0.60 & 0.20 \\
\hline 3 & 0.234 & 0.40 & 2.10 & 1.10 & 0.90 & 1.65 & 4.20 & 1.40 & 1.20 & 0.90 \\
\hline 4 & 0.234 & 0.80 & 1.80 & 0.90 & 0.35 & 1.05 & 1.75 & 1.35 & 1.30 & 0.50 \\
\hline 5 & 0.234 & 1.20 & 1.70 & 1.30 & 0.25 & 1.50 & 0.70 & 1.50 & 1.20 & 0.50 \\
\hline 6 & 0.276 & 0.40 & 2.50 & 1.40 & 0.85 & 2.00 & 5.20 & 2.30 & 0.70 & 1.80 \\
\hline 7 & 0.276 & 0.80 & 2.30 & 0.90 & 0.55 & 0.95 & 0.50 & 1.10 & 1.50 & 0.80 \\
\hline 8 & 0.276 & 1.20 & 1.20 & 0.90 & 0.55 & 1.15 & 2.70 & 1.70 & 0.90 & 0.30 \\
\hline 9 & 0.348 & 0.40 & 2.60 & 0.40 & 0.50 & 0.60 & 2.30 & 1.60 & 0.80 & 1.80 \\
\hline 10 & 0.348 & 0.80 & 1.70 & 0.70 & 0.15 & 0.75 & 0.90 & 0.85 & 0.90 & 0.80 \\
\hline 11 & 0.351 & 0.40 & 2.70 & 0.80 & 0.55 & 1.40 & 4.00 & 1.80 & 1.00 & 1.70 \\
\hline 12 & 0.351 & 0.80 & 2.50 & 1.10 & 0.50 & 1.60 & 4.50 & 2.40 & 0.90 & 1.60 \\
\hline 13 & 0.422 & 0.40 & 2.90 & 0.70 & 0.45 & 0.90 & 4.60 & 1.50 & 1.20 & 1.70 \\
\hline 14 & 0.422 & 0.80 & 2.90 & 0.60 & 0.30 & 0.60 & 3.60 & 1.40 & 1.10 & 1.80 \\
\hline 15 & 0.422 & 1.20 & 2.10 & 0.80 & 0.85 & 0.85 & 4.00 & 1.40 & 1.30 & 0.80 \\
\hline 16 & 0.508 & 0.40 & 3.30 & 0.80 & 0.50 & 0.80 & 3.50 & 1.70 & 0.50 & 2.80 \\
\hline 17 & 0.508 & 0.80 & 3.00 & 0.60 & 0.45 & 0.60 & 2.45 & 0.75 & 1.00 & 2.00 \\
\hline 18 & 0.508 & 1.20 & 2.70 & 1.50 & 0.60 & 1.60 & 3.10 & 2.10 & 1.00 & 1.70 \\
\hline 19 & 0.508 & 1.40 & 2.00 & 1.00 & 0.45 & 1.10 & 2.85 & 1.45 & 1.30 & 0.70 \\
\hline 20 & 0.524 & 0.40 & 3.20 & 0.70 & 0.50 & 1.15 & 4.00 & 2.40 & 1.00 & 2.20 \\
\hline 21 & 0.524 & 0.80 & 3.00 & 1.10 & 0.55 & 1.40 & 2.90 & 2.90 & 1.10 & 1.90 \\
\hline 22 & 0.524 & 1.20 & 2.80 & 1.60 & 0.60 & 1.85 & 3.00 & 2.20 & 1.00 & 1.80 \\
\hline 23 & 0.524 & 1.40 & 2.00 & 1.00 & 0.55 & 1.10 & 2.55 & 1.35 & 1.20 & 0.80 \\
\hline & & & & & & & & & & \\
\hline
\end{tabular}

Tabel 6. Tabel hasil rekapitulasi loncatan hidrolik

\begin{tabular}{|c|c|c|c|c|c|c|c|c|c|c|}
\hline \multirow{2}{*}{ No } & Q & $\mathrm{a}$ & $\mathrm{y}_{2}$ & $\mathrm{y}_{3}$ & $\mathrm{~V}_{2}$ & $v_{3}$ & $\mathrm{~L}_{\mathrm{j}}$ & $E_{1}$ & $E_{2}$ & \multirow{2}{*}{$\Delta \mathrm{E}$} \\
\hline & $\mathrm{L} /$ detik & $\mathrm{cm}$ & $\mathrm{cm}$ & $\mathrm{cm}$ & $\mathrm{cm} / \mathrm{detik}$ & $\mathrm{cm} /$ detik & $\mathrm{cm}$ & $\mathrm{cm}$ & $\mathrm{cm}$ & \\
\hline 1 & 0.108 & 0.400 & 0.750 & 1.050 & 18.987 & 13.562 & 0.550 & 0.934 & 1.144 & 0.210 \\
\hline 2 & 0.181 & 0.400 & 1.000 & 1.350 & 23.816 & 17.641 & 0.950 & 1.289 & 1.509 & 0.220 \\
\hline 3 & 0.234 & 0.400 & 1.650 & 1.400 & 18.660 & 21.992 & 4.200 & 1.827 & 1.647 & -0.181 \\
\hline 4 & 0.234 & 0.800 & 1.050 & 1.350 & 29.323 & 22.807 & 1.750 & 1.488 & 1.615 & 0.127 \\
\hline 5 & 0.234 & 1.200 & 1.300 & 1.300 & 20.526 & 20.526 & 0.700 & 1.515 & 1.515 & 0.000 \\
\hline 6 & 0.276 & 0.400 & 2.000 & 2.300 & 18.158 & 15.789 & 5.200 & 2.168 & 2.427 & 0.259 \\
\hline 7 & 0.276 & 0.800 & 0.950 & 1.100 & 66.029 & 33.014 & 0.500 & 3.172 & 1.656 & -1.517 \\
\hline 8 & 0.276 & 1.200 & 1.150 & 1.700 & 31.579 & 21.362 & 2.700 & 1.658 & 1.933 & 0.274 \\
\hline 9 & 0.348 & 0.400 & 0.600 & 1.600 & 76.316 & 28.618 & 2.300 & 3.568 & 2.017 & -1.551 \\
\hline 10 & 0.348 & 0.800 & 0.750 & 0.850 & 61.053 & 53.870 & 0.900 & 2.650 & 2.329 & -0.321 \\
\hline 11 & 0.351 & 0.400 & 1.400 & 1.800 & 32.989 & 25.658 & 4.000 & 1.955 & 2.136 & 0.181 \\
\hline 12 & 0.351 & 0.800 & 1.600 & 2.400 & 28.865 & 19.243 & 4.500 & 2.025 & 2.589 & 0.564 \\
\hline 13 & 0.422 & 0.400 & 0.900 & 1.500 & 61.696 & 37.018 & 4.600 & 2.840 & 2.198 & -0.642 \\
\hline 14 & 0.422 & 0.800 & 0.600 & 1.400 & 92.544 & 39.662 & 3.600 & 4.965 & 2.202 & -2.763 \\
\hline 15 & 0.422 & 1.200 & 0.850 & 1.400 & 65.325 & 39.662 & 4.000 & 3.025 & 2.202 & -0.823 \\
\hline 16 & 0.508 & 0.400 & 0.800 & 1.700 & 83.553 & 39.319 & 3.500 & 4.358 & 2.488 & -1.870 \\
\hline 17 & 0.508 & 0.800 & 0.600 & 0.750 & 111.404 & 89.123 & 2.450 & 6.926 & 4.798 & -2.127 \\
\hline 18 & 0.508 & 1.200 & 1.600 & 2.100 & 41.776 & 31.830 & 3.100 & 2.490 & 2.616 & 0.127 \\
\hline 19 & 0.508 & 1.400 & 1.100 & 1.450 & 41.776 & 46.098 & 2.850 & 1.990 & 2.533 & 0.544 \\
\hline 20 & 0.524 & 0.400 & 1.150 & 2.400 & 59.954 & 28.728 & 4.000 & 2.982 & 2.821 & -0.161 \\
\hline 21 & 0.524 & 0.800 & 1.400 & 2.900 & 49.248 & 23.775 & 2.900 & 2.636 & 3.188 & 0.552 \\
\hline 22 & 0.524 & 1.200 & 1.850 & 2.200 & 37.269 & 31.340 & 3.000 & 2.558 & 2.701 & 0.143 \\
\hline 23 & 0.524 & 1.400 & 1.100 & 1.350 & 62.679 & 51.072 & 2.550 & 3.102 & 2.679 & -0.423 \\
\hline
\end{tabular}




$$
\begin{array}{lll}
\mathrm{E}_{2}=\mathrm{y}_{3}+\frac{\mathrm{V}^{2}}{2 \mathrm{~g}} & =1.05+\frac{183.929^{2}}{2.981} & =1.144 \mathrm{~cm} \\
\mathrm{E}_{\mathrm{c}}=\frac{\mathrm{V}}{\sqrt{\mathrm{gD}}} & =\frac{0.570}{\sqrt{981.0 .04}} & =0.909 \mathrm{~cm} \\
\mathrm{y}_{\mathrm{c}}=\sqrt[3]{\frac{\mathrm{q}^{2}}{\mathrm{~g}}} & =\sqrt[3]{\frac{0.142^{2}}{981}} & =0.027 \mathrm{~cm}
\end{array}
$$

c) Kehilangan energi

$$
\begin{aligned}
\Delta \mathrm{E} & =\mathrm{E}_{2}-\mathrm{E}_{1}=1.144-0.934 \\
& =0.210 \mathrm{~cm}
\end{aligned}
$$

\section{Kesimpulan}

Berdasarkan hasil dan pembahasan dapat disimpulkan sebagai berikut:

1) Pada variasi debit dan bukaan pintu air menghasilkan berbagai bentuk perubahan aliran di bagian hilir pintu. Di antaranya perubahan kedalaman, kecepatan, panjang loncatan hidrolik, bilangan Froude dan jenis alirannya.

2) Pada pengamatan yang dilakukan di Laboratorium Hidrolika Universitas Tadulako semakin tinggi bukaan pintu air pada debit yang sama, panjang loncatan hidrolik, nilai bilangan Froude dan kecepatan yang dihasilkan pada bagian hilir pintu semakin menurun dan semakin rendah bukaan pintu air pada debit yang sama, panjang loncatan hidrolik, nilai bilangan Froude dan kecepatan yang dihasilkan pada bagian hilir pintu semakin meningkat. Karakteristik jenis aliran yang dihasilkan pada variasi debit dan bukaan pintu air adalah superkritis dan subkritis.

Saran yang dapat disampaikan untuk penelitian yang akan datang adalah sebagai berikut:

1) Sebaiknya pada pengukuran kecepatan dan debit dilakukan menggunakan alat ukur seperti tabung pitot, Thompson dan sejenisnya.

2) Aklirik yang digunakan sebaiknya diganti, karena meskipun sudah dibersihkan aliran yang lewat tidak terlihat jelas.

3) Bak penampung dibersihkan setiap kali proses running, agar sedimen yang masuk dalam bak penampung tidak mengendap terlalu lama sehingga air yang dialirkan tetap jernih.

4) Untuk penelitian yang akan datang diperhatikan lagi untuk pengamatan lebih detail pada kondisi kedalaman tepat setelah bukaan pintu

\section{Daftar Pustaka}

[1] Pudyono dan Sunik, "Penentuan Kedalaman dan Pola Gerusan Akibat Aliran Superkritis di Hilir Pintu Air Menggunakan End Sill dan Buffle Block dengan Simulasi Model Integrasi Numerik", Jurnal Rekayasa Sipil, vol. 7, no. 2, p. 118, 2013.
[2] B. Triatmodjo, Hidrolika II. Yogyakarta: Beta Offset, 2015.

[3] W.H. Graf and M. Altinakar, Fluvial Hydraulics Flow and Transport Processes in Channel of Simple Geometry, England: John Wiley \& Sons Ltd., 1998.

[4] S.R. Ain, Kajian Loncatan Hidrolik (Hydraulic Jump) Pada Bukaan Pintu Air Saluran Irigasi Berbentuk Segi Empat Skala Laboratorium, Mataram: Universitas Mataram, 2016.

[5] D. Priyantoro, Teknik Pengangkutan Sedimen. Malang: Fakultas Teknik Universitas Brawijaya, 1987.

[6] Pudyono, "Pengaruh Pemasangan Bangunan Peninggi Muka Air (Subweir) Terhadap Gerusan Yang Terjadi di Hilir Bendung", Jurnal Rekayasa Sipil, vol. 4, no. 2, p. 99, 2010.

[7] V.T. Chow, Hidrolika Saluran Terbuka, Jakarta: Erlangga, 1997.

[8] Suryatman, V.K. Sugiharto, and E.N. Rosalina, Hidrolika Saluran Terbuka (Open Channel, Jakarta: Erlangga, 1985.

[9] R.K.G. Raju, Aliran Melalui Saluran Terbuka, Jakarta: Erlangga, 1986.

[10] K. Subramanya, Flow In Open Channels, New Dehi: McGraw-Hill Publishing Company, 1986.

[11] A.A. Latif1, M.S. Pallu, F.Maricar, and M.P. Hatta, "Pengaruh Tinggi Bukaan Pintu Air Terhadap Bilangan Froude Dengan Dasar Tanah Lempung Pada Saluran Terbuka", Prosiding Seminar Nasional Teknik Sipil, p. 181, 2019.

[12] Nurnawaty, A. Rakhim, M. Safitri, and Muhaemina, "Loncatan Hidrolik Pada Hilir Pintu Sorong Dengan dan Tanpa Ambang Akibat Variasi Tinggi Bukaan Pintu", Jurnal Teknik Hidro, vol. 14, no. 1, p. 1, 2021.

[13] A. Binilang, "Perilaku Hubungan Antar Parameter Hidrolis Air Loncat Melalui Pintu Sorong Pada Saluran Terbuka", Jurnal Ilmiah Media Engineering, vol. 4, no.1, p. 41, 2014.

[14] A. Rizaldy, R. Musa, and A. Mallombasi, "Kalibrasi Koefisien Debit Model Bukaan Pintu Sorong Pada Saluran Terbuka (Uji Laboratorium)", Jurnal Teknik Sipil MACCA, vol. 6, no. 1, p. 1, 2021.

[15] B. Sujatmoko, N. Silia, and Mudjiatko, "Pengaruh Parameter Aliran Terhadap Letak Awal Loncat Air Melalui Pintu Sorong Tegak (Sluice Gate)", Jurnal Teknik Sipil SENDI, vol. 2, no. 2, p. 57, 2021. 